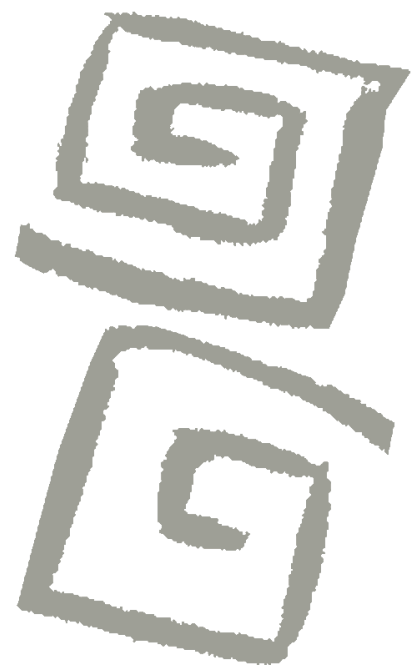

\title{
Volver a pensar en salud: programas y territorios
}

\author{
Thinking about health once again: programs and \\ territories
}

${ }^{1}$ Doctor en Salud Colectiva. Director del Instituto de Salud Colectiva, Universidad Nacional de Lanús, Buenos Aires, Argentina. $\triangle$ (iD
RESUMEN Este artículo, de naturaleza conceptual, discute desde la teoría crítica la lógica programática en el campo sociosanitario como una respuesta técnica sin preguntas, frente a los territorios entendidos como espacios con preguntas a la espera de traducciones. El propósito es poner en discusión la lógica programática, herencia de la planificación y expresión de la razón instrumental, para desde allí discutir la concepción temporo-espacial como eje para pensar y actuar frente a la complejidad de lo social, reconociendo otros saberes y prácticas. Las preguntas, las respuestas, los saberes y el hacer en el campo sociosanitario constituyen los ejes de la reflexión sustentada en conceptos que buscan desarmar el proyecto ideológico que representan los programas mediante el análisis de su base científica (componente epistemológico de la técnica), que es antagónico a cualquier proyecto de emancipación.

PALABRAS CLAVES Epistemología; Planificación Social; Planes y Programas de Salud; Percepción del Tiempo; Incertidumbre; Medio Social.

ABSTRACT This article, of a conceptual nature, uses critical theory to discuss the programmatic logic within the sociosanitary field as a technical answer without any questions, provided to territories or spaces with questions awaiting translation. The purpose is to put programmatic logic, which is the legacy of public health planning and an expression of instrumental reason, into discussion, and in this way examine the temporal-spatial conception as an axis for thinking and acting within the complexity of the social world, recognizing other knowledge and practices. The questions, answers, knowledge and actions in the sociosanitary field constitute the focus of a reflection rooted in concepts that seek to deconstruct the ideological project represented by health programs through an analysis of their scientific basis (the epistemological component of the technical), which is antagonistic to any emancipatory project.

KEY WORDS Epistemology; Social Planning; Health Programs and Plans; Time Perception; Uncertainty; Social Environment. 


\section{INTRODUCCIÓN}

Los intelectuales son, en cuanto detentores del capital cultural, una fracción (dominada) de la clase dominante. Pierre Bourdieu ${ }^{(1)}$

Este texto se estructura sobre la base de las siguientes preguntas: ¿por qué las políticas en el campo sociosanitario tienden a expresarse a través de programas?; ¿son los programas la mejor respuesta desde el Estado a las necesidades de los conjuntos sociales, en términos de ampliación de derechos y reducción de desigualdades?; ¿los conocimientos de los trabajadores del campo sociosanitario alcanzan para abordar la complejidad de lo social?; ¿necesitan saber más, o desaprender mucho de lo aprendido?; ¿se trata solo de un conflicto de lo político, o hay además un conflicto epistemológico?

El propósito de estas preguntas es poner en discusión, desde la teoría crítica $^{(2)}$, la planificación y la programación social como expresión de la razón instrumental ${ }^{(3,4)} y$, desde allí, entender el territorio como espacio de lo singular y sitio del hacer, donde lo relacional y lo simbólico se expresan atravesados por capitales y campos que exceden la simplicidad epistemológica que sustentan los programas ${ }^{(5,6,7,8)}$. Esa dinámica exige una cartografía permanente que acompañe diacrónicamente al territorio, el cual no es estático, ya que se reconfigura de manera permanente ${ }^{(9)}$. De este modo, procuramos cuestionar el proyecto ideológico que representan los programas, mediante el análisis de su base científica, componente epistemológico de la técnica, al cual entendemos como antagónico a cualquier proyecto de emancipación ${ }^{(10)}$. Nos proponemos buscar preguntas, y no repetir respuestas, por lo que recurrimos a distintos conceptos, utilizando la teoría como caja de herramientas ${ }^{(11)}$, con la intención de volver a pensar en salud, más allá de la biomedicina ${ }^{(12,13)}$.

\section{LA CIENCIA NO PIENSA Y LA PEREZA DE LA FILOSOFÍA}

Mario Testa señala la ausencia de marcos teóricos que superen las determinaciones biológicas en los cinco grandes ámbitos del poder técnico en salud: la docencia, la investigación, los servicios, la administración y la población ${ }^{(13)}$. Es decir que tanto los profesionales, como los técnicos y la población están imbuidos de las concepciones biológicas que desplazan lo social del proceso salud-enfermedad-atención, lo cual facilita la medicalización y la expansión de la biopolítica ${ }^{(14)}$.

Cuando Heidegger dice: "la ciencia no piensa", nos señala que la ciencia no se mueve en la dimensión de la filosofía y que, aunque depende de ella, olvida pensar y, en ese olvido, sacrifica la pasión que representa la pregunta. $\mathrm{Y}$ ante la falta de preguntas, domina lo instrumental que, con sus destellos y brillos, encandila y produce "parpadeos"(15). Pensar es tratar de escapar de las respuestas totalizantes que niegan que "la polisemia es el elemento en el que el pensamiento debe moverse para ser riguroso"(15 p.98). A su vez, Bachelard destaca "la pereza de la filosofía" al señalar el poco espacio que ocupa en ella la filosofía de las ciencias y afirma que "el pensamiento es una fuerza, no una substancia" 116 p.20). En línea con esa argumentación, recuperamos a Marcuse, quien advierte sobre la capitulación del pensamiento ${ }^{(17)}$, y a Tovillas, que destaca el Ilamado a la reflexividad que hace Bourdieu:

\footnotetext{
...los individuos casi todo lo ignoran por una doble razón: por la racionalidad limitada de la cual disponen (o por el tipo de racionalidad), y porque lo ordinario, al naturalizarse por la costumbre, no forma parte de un juicio reflexivo, es decir, no es puesto en cuestión por el individuo, volviéndose evidente producto del hábito social. ${ }^{(18 \text { p.47) }}$
}

En línea con el ejercicio de la reflexividad que propone Bourdieu, vale retomar el concepto de elucidación formulado por 
Castoriadis: "saber lo que se piensa y pensar lo que se hace ${ }^{\prime \prime(19)}$, para pensar desde una praxis fundante, dado que la fundamentación no tiene efecto de transformación, y fundar y fundamentar no son sinónimos ${ }^{(20)}$, como tampoco lo son ser jugador o ser comentarista de un juego. En este sentido, resulta necesario diferenciar entre discursos, prácticas e impacto de las prácticas, para no equivocar el camino.

La pregunta es central para el pensamiento, por lo que debemos renunciar a las "respuestas de laboratorio". Preguntar, pensar y hacer en el campo sociosanitario constituyen los ejes de la reflexión de este trabajo, lo que nos obliga también a pensarnos en el contexto de América Latina, para evitar los cientificismos $^{(21,22)}$

\section{LOS PROGRAMAS COMO RESPUESTAS}

\section{Raíces históricas}

En el siglo XX, el Estado de Bienestar pensó tres elementos superpuestos para controlar la pobreza y la exclusión: poblaciones objetivos, un conjunto de reglas y prestaciones, y un cuerpo de trabajadores especializados, para lo cual se requería de la identificación de las poblaciones objetivos, su constitución estadística, jurídica y administrativa; la creación de derechos y asignaciones; y la conformación de un cuerpo de trabajadores del campo de lo social que gestione el sistema ${ }^{(23)}$. Esta lógica fue perdiendo legitimidad al demostrarse que saber no es sinónimo de entender y que, por más saber que se desarrolle sobre las poblaciones, no siempre es suficiente para entender las trayectorias singulares personales $\mathrm{y} / \mathrm{o}$ colectivas. Una sobreabundancia de información estadística con métodos y técnicas cada vez más sofisticados no pudo evitar la constitución de sociedades heterogéneas marcadas por las desigualdades ${ }^{(23)}$.

La planificación se origina en la década de 1960 en América Latina, en el marco de la Alianza para el Progreso ${ }^{(24)}$. Sus referencias conceptuales fueron las corrientes sociológicas del estructural-funcionalismo ${ }^{(25)}$ y las teorías económicas desarrollistas. La implementación estuvo atravesada por la polémica entre desarrollo o dependencia, centrada en si el crecimiento era un tema económico o de naturaleza social y política ${ }^{(26,27,28)}$. No es necesario señalar cuál fue la postura que triunfó. La planificación se consolidó como resultado del trabajo teórico realizado por la Comisión Económica para América Latina (CEPAL). La conceptualización dominante fue la del Estado como un lugar de concentración de poder y un ámbito de racionalidad con coherencia interna y capacidad de manejo de la totalidad de su gestión. Esas ideas se demostraron falsas, pero fueron, y son, funcionales a la idea de la planificación como técnica para la solución de los problemas sociales. Así, la atención se centró en el crecimiento económico y no en la cuestión social. Las propuestas consistían en que lo social se solucionaría con posterioridad al desarrollo económico a través del "derrame". La hipótesis, nuevamente, se demostró falsa, ya que los procesos de acumulación no fueron sinónimo de distribución. Faltaba mucho para conocer las investigaciones de Thomas Piketty que demuestran que en los dos últimos siglos los países con más desarrollo económico fueron los que más ampliaron las desigualdades al interior de sus sociedades ${ }^{(29)}$.

El objetivo del desarrollo económico abusó de la planificación como técnica. Su principal error fue reducir lo social a un enfoque administrativo de los problemas, entendiéndolo como administración de las cosas y subestimando el gobierno de las personas. Los planificadores tomaron el camino indicado en el siglo XIX por Saint-Simon, para quien era necesario pasar del gobierno de los hombres a la administración de las cosas ${ }^{(30)}$. Así, los problemas fueron concebidos como de reproducción y crecimiento, pero no se planteaba como problema el cambio ${ }^{(13)}$. Esto derivó, en primer lugar, en el abordaje estructural-funcionalista y, luego, en la teoría general de los sistemas ${ }^{(31,25)}$, que tendían a cosificar lo social(32). 
Los planificadores pensaban que los trabajadores iban a realizar lo estipulado en las normas y en los planes diseñados desde los niveles centrales, para organizar un futuro que entendían como predecible. El reino de la razón instrumental no tuvo límites ideológicos ${ }^{(4)}$ y también el socialismo real cayó rendido ante ese canto de sirenas. El énfasis estaba puesto en el desarrollo de técnicas y herramientas. No era necesario pensar, y esa esperanza en lo instrumental llevó a Freud a calificar al hombre moderno como un dios con prótesis ${ }^{(33)}$.

\section{Raíces epistemológicas}

La planificación se nutre de la matriz epistemológica de la modernidad, que entiende que la naturaleza puede ser controlada y que el hombre debe "tomar posesión de ese

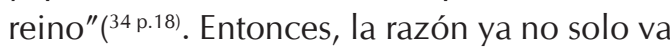
a explicar la realidad, sino que pasa a ser la única forma de producir verdades ${ }^{(35}$ p.12). Así, el mundo es entendido como poseedor de un orden que era necesario descifrar: todo debe tener su razón, no hay espacio para la incertidumbre, conocer el orden que rige al objeto permitirá transformarlo y así dominar la naturaleza y la historia. En ese marco, la verdad aparece como el producto de la enunciación del sujeto cartesiano. La razón se presenta como la gran ordenadora de un sistema que se visualiza como totalizante $y$, a su vez, reducible a la unidad (el uno que lo explica todo). Madel Luz afirma que el conocimiento "será interventor y clasificador" ${ }^{\prime \prime 34}$ ${ }^{\text {p.4) }}$. En este sentido, Boaventura Santos señala que la ciencia moderna reduce la complejidad al concebir que para conocer es necesario dividir y clasificar, para luego establecer relaciones ${ }^{(10)}$. Esa forma de entender la ciencia sienta las bases de la creencia en la infalibilidad del conocimiento, la solidez del discurso y la verdad científica, en la que el hombre aparece reducido a la conciencia, y la ideología reemplaza a la mitología ${ }^{(34)}$. Santos califica a esa racionalidad-que Horkheimer y Adorno designan como instrumental- con el adjetivo de indolente, al resistirse al cambio en las rutinas y transformar intereses hegemónicos en conocimientos verdaderos, que los universitarios suelen repetir como verdades universales, sin poder reconocer que muchas veces solo representan la "verdad europea", lo que expresa la colonización de su pensamiento ${ }^{(10)}$.

Los egresados universitarios tienen, en general, una mirada reducida de los problemas; sin embargo, se sienten habilitados para formular programas que abordan la complejidad de lo social. Desconocen que el programa dará cuenta, a lo sumo, de la dimensión del problema relacionada con la especificidad de su conocimiento, pero no de la totalidad de las dimensiones que componen el problema. La persistencia en América Latina de las Ilamadas "enfermedades olvidadas" -tuberculosis, chagas, paludismo, sífilis, etc.-, el crónico déficit habitacional, el agravamiento de la cuestión ambiental y/o la existencia de porcentajes importantes de población sin servicios de agua y cloacas -a pesar de las declaraciones internacionales de cobertura del $100 \%$ que se vienen realizando desde mediados del siglo pasadoson algunos de los ejemplos que demuestran la permanencia de los problemas a pesar de la multiplicidad de programas existentes. Esa situación expresa que más allá de la técnica para la solución de esos problemas, hay en juego dimensiones político-económicas e ideológico-culturales que los constituyen como problemas complejos y que superan la simplificación que la razón instrumental hace de ellos ${ }^{(4)}$.

\section{Escolástica y universidad}

Las universidades surgen en Europa entre los siglos XII y XIII, en el marco de la escolástica -corriente filosófica teológica medieval- cuyo método de trabajo era el principio de autoridad, basado en que una proposición era aceptada solo por el hecho de estar afirmada en un texto considerado verdadero. Y como los textos eran los escritos sagrados, funcionaban como referencias ineludibles para la interpretación de la realidad 
y sus problemas. Desde esta perspectiva, los problemas debían adaptarse a lo que estaba escrito, es decir, la realidad expresaba el error si contradecía al texto. El saber pasó a ser concebido como universal y objetivo y, por lo tanto, no necesitaba ser contextualizado. Esas ideas, incorporadas por Santo Tomas a la iglesia católica, constituyen la matriz que estructuró las universidades del mundo occidental y el pensamiento eurocéntrico.

La escolástica también sentó las bases del derecho natural cuyas ideas se expresaban en cuatro proposiciones ${ }^{(9)}$ : 1) una cosa se define por su esencia; 2) definir esa esencia genera competencia entre sabios (la iglesia, el príncipe o el sabio) que son las voces autorizadas para definirla; 3) el derecho natural no puede remitir a un estado que preceda a la sociedad; 4) lo primero es el deber (no existe la idea del derecho). Los escolásticos oponen la acción a la pasión, y tienen una representación estática de la realidad que domina en la razón moderna ${ }^{(36)}$. Esto naturaliza una concepción temporoespacial que persiste hasta nuestros días, sobre la cual descansa la planificación y, por ende, la programación.

Para salir de la escolástica es necesario invertirla, de manera tal que sean los problemas los que provoquen a los textos y así, en vez de textualizar los problemas, se problematicen los textos ${ }^{(37)}$. De esas nuevas prácticas podrían surgir otros textos, no en el sentido de verdades universales, sino en el sentido de saberes situados ${ }^{(38,39)}$. Ello exige trabajar los problemas a partir de preguntas, y no de respuestas de las cuales se desconocen las preguntas; no jerarquizar solo la verdad científica, sino también la importancia social de la aplicación del conocimiento ${ }^{(40)}$. Hemos demorado mucho en aprender que las disciplinas no siempre coinciden con los problemas y que, a lo sumo, pueden cubrir parte de su complejidad ${ }^{(41)}$. Pero, aun así, se continúa negando que el mundo de las experiencias es mayor que el mundo del conocimiento $^{(10)}$, lo que nos muestra que hay urgencia de otras epistemologías.

\section{Planificación y razón moderna}

La planificación expresa los principios epistemológicos de la razón moderna -actores racionales, desarrollo y progreso- la cual se relaciona con una idea del tiempo que tiende a ampliar el futuro y reducir el presente $^{(10)}$. De allí que la planificación esté presente en un amplio espectro ideológicopolítico que pretende hacer sencillo y predecible el comportamiento de los sujetos (certidumbre). Esa fortaleza de la que también presume la programación es, a su vez, la mayor debilidad, ya que los problemas sociales -en su mayoría- se caracterizan por su complejidad, su carácter relacional y situacional y, por lo tanto, por su singularidad. De allí deviene la incertidumbre que caracteriza a lo social.

La planificación aparece como una fórmula mágica que, una vez aplicada, por simple evolución, permite una situación deseada. Toma de los escolásticos la idea de ubicuidad, en tanto capacidad de encontrarse en más de un sitio a la vez. Es así que, como técnica, alcanza amplia cobertura disciplinar, y no menos confusión conceptual. Se desconoce que lo propio del plan es que falle y que, frente a los problemas complejos, los resultados son situacionales: buenos para unos y malos para otros ${ }^{(41)}$. La planificación hereda la lógica del Discurso del método y del espíritu normativo que tiene el pensamiento y la obra de Descartes ${ }^{(42)}$.

La planificación se basa en las matemáticas, pilar de la racionalidad fundante de la ciencia que permite la construcción de un método para la búsqueda de certezas. De allí su obsesión por contar, desde la aritmética, pero no de contar, en tanto narrar. La razón aparece como el camino hacia la verdad, así el mundo y el cuerpo serán entendidos como máquinas ocultas tras ecuaciones que pueden definirse algebraicamente ${ }^{(4)}$. El pensamiento, al quedar asociado a la matemática, separa al sujeto del objeto como premisa de la abstracción. El imperativo será que la razón debe enfrentar a la tradición, por lo que se producen saberes y prácticas descontextualizadas. El Iluminismo va a reducir la ciencia 
al criterio del cálculo y lo que no se adapte será sospechado de no ser científico. Es en este sentido que Adorno y Horkheimer consideran totalitario al iluminismo ${ }^{(4)}$.

La discusión sobre la planificación puede abordarse como un problema epistemológico o instrumental (técnicas y métodos). La visión predominante es la instrumental, que ha buscado el éxito perfeccionando técnicas y/o métodos y desconociendo el problema epistemológico que la sustenta. En la Figura 1 se representa el eje históricoconceptual que va de la planificación normativa a la planificación estratégica, eje del cual Mario Testa se despega enunciando el pensamiento estratégico (pensamiento relacional) ${ }^{(43)}$. Pero la figura quedaría inconclusa si no señalamos la existencia previa de una razón instrumental propia del sujeto cartesiano, que excede a la planificación, y sobre la cual esta se asienta.

La ausencia de una reflexión epistemológica es el problema de la planificación -y

PROBLEMA INSTRUMENTAL (TÉCNICA Y MÉTODOS)

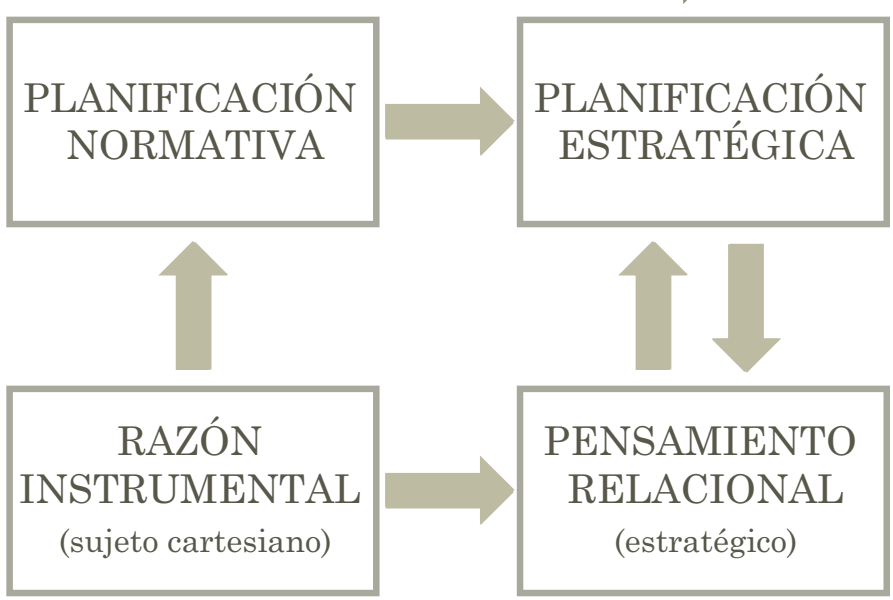

PROBLEMA EPISTEMOLÓGICO de buena parte de la ciencia- lo cual termina transformándose en una prisión ${ }^{(13,44)}$ para los científicos, al llevarlos a una "encerrona" teórica en la que los saberes se tornan dogmas y se pierde la capacidad de formular preguntas porque abundan las respuestas. Nietzsche señalaba hace más de un siglo que toda convicción era una cárcel|(20).

Carlos Matus y Mario Testa sustentan las críticas a la planificación tanto en cuestiones epistemológicas, como metodológicas, lo cual se plasma en un seminario(45) en el que confluyen ambos y que influencia varias publicaciones posteriores que reflexionan sobre la crisis de la planificación y dirigen su mirada hacia el gobierno de las instituciones y de la sociedad $^{(46,47,48)}$. Tanto Testa como Matus, en sus últimas producciones, abandonan la idea de planificación.

Las críticas a la planificación exceden el campo sociosanitario. Henry Mintzberg, economista canadiense y profesor de la McGill University, uno de los grandes gurúes del management a nivel mundial, señala el ocaso de la planificación estratégica al describirla -irónicamente- como el sistema formal que las empresas tienen para elaborar y operacionalizar las estrategias que ya poseen. Dentro de la planificación, Mintzberg critica el desconocimiento de las estrategias como patrones emergentes, ligadas a lógicas de procesos, en lugar de ser entendidas como la capacidad de predecir el futuro, como pretenden los planificadores. Mintzberg no cree que la estrategia pueda ser formalizada, ya que la considera creativa y no ajustada a fórmulas, capaz de envolver procesos complejos, sofisticados, sutiles y hasta inconscientes a nivel individual y/o social. A su vez, señala tres falacias de la planificación estratégica: la falacia de la predicción, la falacia de la independencia y la falacia de la formalización ${ }^{(49)}$.

\section{Planificación y programación}

No es casual que los programas predominen en territorios marcados por las desigualdades: el proyecto político-económico e ideológico-cultural que representan es

Fuente: Elaboración propia. 
antagónico a la disminución de las desigualdades, mucho más al cronificarse en el tiempo ya que, dado su carácter externo a lo local, incrementa las debilidades institucionales del Estado, allí donde más se lo necesita. La lógica de los programas es funcional a cuatro cuestiones: las fuertes desigualdades sociales ${ }^{(23)}$; los bajos niveles de ciudadanía; las bajas capacidades de gobierno en los funcionarios del Estado a nivel local, regional y nacional(32); y los obstáculos epistemológicos de los egresados universitarios para entender el juego social ${ }^{(8,50,51)}$.

Las acciones de gobierno, al quedar en manos de universitarios, pueden reducirse a los contenidos de sus saberes, los que estructuran respuestas sin preguntas bajo el formato de programas, y así niegan consciente o inconscientemente lo político. Es por esto que las diferencias ideológicas que se observan en una elección, entre los partidos políticos que participan del juego democrático, se reducen al analizar las acciones que realizan cuando llegan al gobierno. Esta situación ¿es solo una cuestión de recursos de poder o hay también cuestiones epistemológicas en juego? La pregunta nos remite a la articulación entre lo político y las políticas: lo político (nivel ontológico relacionado al poder) representa un conjunto de valores y principios que pueden opacarse por el diseño y la ejecución de las políticas (nivel óntico que refiere a lo empírico) ${ }^{(52)}$.

Los cuadros técnicos "no saben que no saben, y entonces, hacen lo que saben", dice Matus ${ }^{(41)}$ al señalar cómo ese conocimiento específico que constituye la especialidad del profesional es insuficiente frente a la complejidad de lo social. Por tal motivo, la única respuesta que pueden imaginar son "los programas", diseñados a partir de un conocimiento sincrónico y descontextualizado que constituye una mirada acotada sobre la complejidad del territorio. La razón instrumental es dominante en las universidades, y tiene poco que ver con las preguntas/ problemas que surgen del territorio, así el saber disciplinario queda hipnotizado con respuestas que aparecen como soluciones mágicas.
Concebir la planificación como una cuestión técnica llevó a un sinnúmero de adjetivaciones, por ejemplo: administrativa, económica, regional, rural, urbana, social, sectorial, anticíclica, centralizada, descentralizada, compensadora, democrática, económica, estructural, flexible, imperativa, indicativa, global o integral, normativa, operativa, participativa, por etapas, estratégica, situacional $^{(41,53)}$. Estos adjetivos procuran maquillar lo que es imposible de ocultar. Los técnicos saben pero, en general, no piensan, por lo que toman lo instrumental como un todo explicativo. De allí que tengan $-y$ anhelen aún más- herramientas para administrar objetos, a los cuales conciben como inertes, pero no están preocupados por obtener conocimientos acerca de cómo gobernar personas y trabajar con problemas complejos y cadenas de problemas, y así siguen pensando que juegan solos.

La cultura de la planificación consistió -y aún consiste- en planificar a nivel central, identificando unilateralmente los problemas y las respuestas, y administrando los programas en los que se desagrega el plan a nivel local. El texto de referencia del campo de la salud en América Latina sobre el método de planificación fue la publicación realizada por CENDES/OPS bajo el título Programación en salud $^{(54)}$. Es así que la programación se define desde una concepción mecánica, infalible y sin fallas, una verdadera máquina, que permite una dinámica lineal:

La programación es la reproducción conceptual de las actividades y tareas que hay que realizar para lograr un resultado -un producto- previamente definido y las secuencias correspondientes. Un programa es el resultado de esa elaboración con las asignaciones -de recursos y responsabilidades administrativas- que garanticen la viabilidad de la propuesta ${ }^{(43)}$.

Plan integrado, esquema o conjunto ordenado de acciones, actividades, métodos y procedimientos encaminados a la consecución de un objetivo (resolución de un problema u obtención de 
un resultado). Acciones orientadas a prever y disponer los recursos para lograr determinados fines. Toda actividad programada se descompone en etapas $y$ éstas en operaciones ${ }^{(55)}$.

Un programa de salud está constituido por un conjunto de recursos reunidos y aplicados para proporcionar a una población definida unos servicios organizados de forma coherente en el tiempo y en el espacio en vistas a conseguir los objetivos deteminados en relación a un problema de salud determinado(56).

Los programas sociosanitarios $-y$ su raciocinio- Ilevan más de 50 años y, dada la persistencia de los problemas, no pareciera ser la manera más eficaz ni más eficiente para resolverlos. Sí, quizá, la más cómoda y funcional a la racionalidad de los universitarios. Los programas se multiplican en los organigramas de un gobierno siguiendo los nombres de las facultades o la estructura curricular de sus carreras dominantes; en tanto, en los ministerios de salud, se sigue la anatomía del cuerpo humano (sistemas, órganos o partes de un órgano) o se centran en determinadas enfermedades. En promedio encontramos entre 25 y 50 programas en los distintos ministerios de salud, tanto a nivel nacional, como de las provincias argentinas. El programa es la inserción vertical en el territorio, respuesta a lo individual y recorte de la realidad que parte de la clasificación como condición del conocimiento, pero que desconoce que no es el conocimiento, ya que este tiene la potencia de disolver la clasificación ${ }^{(4)}$.

Al analizar las gestiones de diferentes gobiernos podemos ver que los programas terminan siendo la expresión más desarrollada de la política, de allí la obturación de lo político que los programas realizan. A la gente le Ilegan "respuestas" más o menos parecidas a las del gobierno anterior y bastante alejadas de las promesas de la campaña electoral. El programa, en tanto técnica que determina el hacer, elimina lo político -valor que le da sentido al hacer-y lo convierte en política neutra y universal, y así transforma intereses hegemónicos en conocimientos verdaderos $^{(10)}$. Uno de los tantos ejemplos en este sentido se encuentra en la obra de Marcia Angell(57), ex editora responsable de The New England Journal of Medicine, en la que señala la falsedad de la objetividad científica al demostrar los intereses económicos de la industria farmacéutica en la construcción de evidencias.

A partir de los fracasos de la planificación social y económica en América Latina, tanto Mario Testa, como Carlos Matus (entre otros), reconocieron una distancia infranqueable entre los modelos racionales de la planificación y el juego social ${ }^{(13,32,41,43)}$. Esta discusión no es menor en nuestros países, en los que se nos propone seguir planes y/o ejecutar programas como si fueran soluciones mágicas.

\section{La fragmentación de los sujetos, los territorios y los problemas}

Los programas se proponen como respuestas a los "diagnósticos técnicos", en general, bajo el formato de enlatados producidos por organismos internacionales. La mayoría de esas propuestas suelen ser modas efímeras, pero se acumulan al interior de las instituciones del Estado como capas geológicas y persisten como racionalidades -en tanto formas de conocimiento- ya sea a través de técnicas, discursos, procesos de trabajo y/o dinámicas organizativas. Lo único que no cambia con el tiempo son los problemas, que no solo aumentan en cantidad, sino que se vuelven más complejos y singulares. En síntesis, los programas no salen del papel y las promesas no se plasman en soluciones. Los sujetos de la ciencia no siempre pueden entender que "las modas técnicas" constituyen el problema y no la solución.

Los programas fueron, y son, las formas de dar respuestas, por parte del Estado, a los problemas y/o demandas de los conjuntos sociales. En sus orígenes, en el campo de la salud, tuvieron mayor impacto ya que enfrentaron situaciones epidemiológicas dominadas por enfermedades de carácter infeccioso que 
requerían, como condición de efectividad, una alta cobertura, por lo que la respuesta se realizó a través de programas centralizados a nivel nacional como, por ejemplo, las campañas de vacunación frente a la epidemia de poliomielitis en los años cincuenta. Pero al complejizarse la situación epidemiológica de los conjuntos sociales -mal Ilamada "transición epidemiológica"(58) - se necesitó incluir otras dimensiones que proponían cambios, como los aspectos relacionados a acciones intersectoriales y/o modos de vida $y$, por lo tanto, la condición de efectividad requería incluir el tema del territorio y la gestión social de los problemas. Allí, los programas debieron enfrentar dimensiones socioculturales y fueron perdiendo efectividad frente a la imposibilidad de traducir los distintos saberes y concepciones del mundo puestos en juego por distintos actores/agentes. Esto señala las limitaciones del pensamiento de la epidemiología moderna centrada en el eje lugar-tiempo-persona, incapaz de reemplazarlo por el eje territorio-historia-sociedad ${ }^{(59)}$.

La modernidad instala la idea de que, en la relación entre ciencia, técnica y sociedad, a la ciencia le correspondían los temas de la naturaleza, mientras que la política se encargaba de los temas de la sociedad ${ }^{(60)}$. En los últimos tiempos, esa relación presenta otros desafíos, dado que "los nuevos" problemas de la cuestión social han roto los límites entre ciencia y política y se presentan como objetos híbridos ${ }^{(60)}$, mezclando dimensiones de la naturaleza y de la sociedad, y desafiando prácticas y saberes tanto de lo político como de lo científico. Esos objetos híbridos interpelan de manera simultánea a la ciencia y a la política, como lo vemos en las violencias, la fertilidad asistida, las nuevas estructuras parentales, los bancos de células madres, la genética y sus aplicaciones, etc. Estos son algunos de los ejemplos que entran en conflicto con los viejos dispositivos conceptuales de lo programático, que se dirigen verticalmente al territorio sin diferenciar culturas ni procesos sociales y le asignan al nivel local muy baja capacidad de tener/producir conocimientos. En esa lógica, los problemas se fragmentan, y los recursos materiales y el personal técnico abocado a la resolución de los problemas se vuelven ineficientes e ineficaces, y en ello colaboran los distintos componentes del programa: estructuras normativas; sistemas de información y evaluación; "expertos"; manuales de procedimientos y de buenas prácticas; evidencias científicas y guías clínicas; etc.

Todo el despliegue programático se realiza bajo el discurso de construir "políticas de Estado", volviendo a la idea de pasteurizar lo social al concebirlo exento de conflictos. La distribución de los recursos económicos, materiales y del personal que lleva adelante los programas, en sus diferentes niveles y funciones, contrasta, en general, con las necesidades de las comunidades asentadas en el territorio, en las que lo relacional ocurre bajo dinámicas muy distintas a las de esos programas. Tenemos allí dos lógicas que no dialogan: una -la de los programas- pensada cual diagrama de Venn y, la otra -la del territorio- que se configura en términos de un nudo borromeo ${ }^{(61)}$.

La mirada desde el programa es reduccionista ya que desconoce las singularidades y los aspectos culturales que se ponen en juego en cada territorio. Así, se cosifica lo social y se lo simplifica sobre la base de "la solución" que proviene de la racionalidad de los técnicos que, en general, residen muy lejos del lugar donde se implementa el programa. La duplicación de las acciones y/o superposición entre diferentes programas es una muestra de la ineficacia e ineficiencia que, en general, no se discute, ya que sus técnicos rara vez entran en comunicación y, a veces, ni se conocen.

Los programas y sus reuniones de capacitación, seminarios, jornadas, etc., producen un efecto de cascada que afecta lo operativo: el nivel nacional convoca al personal de las provincias, estos al personal de los municipios y estos a los responsables de las instituciones territoriales. Los encuentros tienden a caracterizarse por personas portadoras de distintos conocimientos y experiencias, con capacidades técnicas y simbólicas muy distintas y que trabajan en territorios de lo más disímiles. A pesar de ello, se pretende que 
entiendan y apliquen las mismas normas para lograr los mismos resultados: una verdadera apuesta a lo mágico. Las reuniones se programan como si fueran miles los funcionarios y trabajadores del nivel municipal y territorial con disponibilidad de asistir, cuando en realidad son muy pocos o, mejor dicho, son siempre los mismos los que cargan sobre sus espaldas las tareas y los viajes, de los cuales vuelven con distintas normas, sistemas de información, guías y asistencias a capacitaciones. El profesional que asiste a las convocatorias no siempre muestra ni comenta con sus colegas las novedades porque conoce que, en general, la recepción no es la más amistosa. Todo el esfuerzo se compensa -a veces- con un dinero que entra al nivel local a través de los Programas de Transferencia de Renta Condicionada impulsados por los organismos internacionales ${ }^{(62)}$, o por el acceso a viajes -formas encubiertas de turismo científico- a lugares nacionales o internacionales, viáticos o suplementos salariales que complementan los ingresos, aunque no pocas veces esos privilegios producen fragmentación en el colectivo de los trabajadores. Como cada programa crea su propia lógica administrativa, sus procedimientos y formularios, su lenguaje y sus códigos, se transforma en un laberinto al que pueden acceder quienes lo conocen, reforzando desigualdades en los conjuntos sociales por cuestiones administrativas. Los programas atomizan a los habitantes del territorio, los que son reducidos a problemas, carencias o enfermedades que, no pocas veces, serán su única identidad frente al Estado.

¿Los programas son la única forma de relación posible entre el Estado y los conjuntos sociales? Entendemos que no, ya que los programas representan un obstáculo para reducir las desigualdades al fragmentar los problemas, el territorio y los sujetos, y fomentar el asistencialismo, en el cual no hay derechos, sino una oferta que se impone a partir de un diagnóstico externo. El programa solo puede justificarse como parte de lo urgente, pero nunca como parte de lo importante. Su persistencia en el tiempo señala el fracaso en solucionar los problemas. Si analizamos los países con menos desigualdades, notaremos el poco desarrollo que tienen allí los programas ya que "el juego" está centrado en la institucionalidad y el ejercicio de la ciudadanía. Con lo cual, podríamos afirmar que el número de programas de un gobierno es inversamente proporcional a los niveles de ciudadanía que existen en ese país.

\section{LOS TERRITORIOS COMO PREGUNTAS}

Los programas son respuestas sin preguntas. Los especialistas que "saben" y formulan las respuestas a los problemas no parten de preguntas sino de certezas. Los programas expresan las huellas del colonialismo científico en el saber universitario. Vale aquí la advertencia de Nietzsche: "El desierto crece: jay de aquel que esconde desiertos!"(15 p.41). Así, los programas se reproducen, mientras lo territorial se reduce a la participación social, a los agentes sanitarios o promotores territoriales. La lógica programática devuelve como verdades reveladas saberes ancestrales que fueron arrebatados por la ciencia a las propias comunidades, por ejemplo: la formación de cooperativas de trabajo, la lactancia materna, el parto natural, la comensalidad, el cuidado de adultos mayores, los modelos productivos de base familiar, las huertas comunitarias, etc.

En el año 1937, Ortega y Gasset denominó a los profesionales universitarios como los bárbaros modernos, en el sentido de que cada vez sabían más de menos ${ }^{(63)}$. Santos afirma: "La ciencia moderna produce conocimientos y desconocimientos. Se hace del cientista un ignorante especializado y se hace del ciudadano común un ignorante generalizado"164 ${ }^{p .888}$. Esas afirmaciones interpelan a los universitarios en tanto sujetos epistémicos, más allá de la ideología y/o filiación partidaria.

Los saberes científicos son necesarios y muy útiles en determinados casos, pero el territorio necesita $-y$ tiene- otros saberes que no siempre se sustentan en la ciencia, de allí la importancia de una ecología de saberes en permanentes procesos de traducción ${ }^{(10)}$. El 
territorio no necesita de planes y programas sino de ciudadanía y de trabajadores del campo sociosanitario que desarrollen vínculos basados en el cuidado desde lo artesanal de su tarea, en procesos relacionales mediados por lo simbólico ${ }^{(10,65,66,67)}$. Estos trabajadores tienen prácticas muy ricas, impregnadas por "el caos" con el que se les presenta lo social ante sus racionalidades estructuradas en lógicas de orden y clasificación. Esa configuración epistémica produce mucho malestar y no menos sufrimiento, ya que lo que no se entiende se sufre. Para instalar nuevas praxis se debe permanecer fiel a la sentencia de Paulo Freire, quien señaló: "donde los pies pisan, la cabeza piensa"(68). Las dificultades para entender lo territorial y moverse en una dinámica relacional, en escenarios de complejidades crecientes y/o caos, induce al dominio de una lógica centrípeta que reproduce más que produce, y lleva a que los profesionales tiendan a atrincherarse en sus instituciones como forma de defensa ante eso "externo" que incomoda y desestructura, y que cada vez se entiende menos, ya que los problemas son más complejos y más distantes a sus epistemes.

El territorio nos demuestra que la epidermis no es el límite del individuo y que si vamos más allá de la piel de cada sujeto se pueden trascender los factores de riesgo para pensar en términos de interacción y juego social, y descubrir las vulnerabilidades sociales y las lógicas de poder (macro y micro), como también la potencia que subyace en el territorio. Trabajar allí no implica pensar con las categorías de la planificación/programación con las que la mayoría de los universitarios son formados e interpretan lo social.

Las preguntas marcan el camino del pensamiento, y la posibilidad de formularlas se relaciona con la riqueza del marco epistémico y teórico. Enfrentar lo no pensado, y aceptar el derrumbe de las certezas, permitirá realizar preguntas y evitar la naturalización, la queja y/o la anécdota. Por ello no se debe temer abandonar lo conocido que no resulta útil, para aventurarse en lo desconocido en un viaje sin certezas de éxito, apostando y siendo fiel a las apuestas, inscriptos en una lógica del acontecimiento en la que no se predicen los objetivos a futuro, sino que se los reconoce al volver la mirada hacia atrás y se identifica lo construido que, en general, se ubica lejos de lo pensado/imaginado, sobre todo en su trayectoria ${ }^{(69,70)}$.

A priori, adjudicamos al territorio, y a las preguntas que de él surjan, la supremacía sobre cualquier teoría, en el sentido de invertir la escolástica y problematizar los textos, para buscar pistas que permitan conformar un marco conceptual que respete los saberes técnicos que han demostrado eficacia, pero que vaya más allá, para facilitar pensar, entender, interpretar y actuar frente a lo fortuito, lo discontinuo, lo diferente, lo aleatorio, la diseminación y las multiplicidades, que se dan en el territorio. Para todo ello es necesario superar las falsas dicotomías instaladas en el pensamiento: historia/naturaleza, consciente/ inconsciente, cuerpo/alma.

En las líneas que siguen buscamos volver a jerarquizar las preguntas como inicio del pensamiento, para así poder producir encuentros y acontecimientos. No se pretende construir nuevas jaulas de hierro ${ }^{(43)}$, ni prescripciones infalibles. El propósito es poder volver a pensar y, en función de ello, desarrollar praxis que en su devenir construyan espacios de libertad, reduzcan desigualdades, desarrollen ciudadanía y construyan nuevas institucionalidades en los territorios. Esto exige categorías muy diferentes a las utilizadas por la planificación y la programación, por lo que desarrollaremos algunas de esas categorías para discutir la cosmovisión que se nos ha impuesto desde la ciencia universal.

\section{Lugar y territorio}

La geografía crítica diferencia entre lugar y territorio. El primer concepto -el más tradicional- es entendido como la ubicación geográfica de las personas en un tiempo determinado mientras que, el segundo, sostiene que los grupos poblacionales a través de su accionar modifican el medio físico en interacción con otros grupos y construyen -con autonomía relativa- ese lugar donde 
habitan ${ }^{(5)}$. Milton Santos, geógrafo brasilero -nieto de esclavos-, concibe el territorio como el área del acontecer solidario, marcado por la contigüidad de los sujetos y por sus procesos de interrelación que construyen lo identitario en los conjuntos sociales, en los que interviene el territorio al forzar y/o facilitar esas interrelaciones. El territorio no es sinónimo de violencia, es sinónimo de complejidad y caos, sumergido en estructuras que son estructurantes pero a su vez estructuradas por la acción de los sujetos individuales y/o colectivos ${ }^{(5,6,7,7,8,71)}$.

El territorio tiene un carácter dinámico, por lo que debe ser entendido dentro de una lógica procesual, fruto de un conjunto de acciones producidas por actores y objetos. Reconocer el valor social de los objetos no es otra cosa que aceptar que los objetos no son "cosas" sino productos de la acción social ${ }^{(5,6,59)}$. Para Harvey, el territorio es una construcción -a través de un devenir histórico- que expresa las condiciones y los modos de vida de los conjuntos sociales, atravesados por relaciones de poder ${ }^{(71)}$.

El territorio es un caleidoscopio que se complejiza a medida que nos acercamos y, frente a aquello que a la distancia aparecía como homogéneo, toma relevancia lo singular. Las miradas sobre el territorio no hacen más que describir la configuración de una trama laberíntica propia de lo social, atravesada por dimensiones económico-políticas e ideológicas-culturales que reconocemos tanto en lo macro como en lo micro. Asumir el territorio como singular no significa su reducción a la materialidad, sino concebirlo como espacio de lo relacional-simbólico, en el que actúan capitales y campos que se crean y recrean y pueden excederlo. Bourdieu diferencia entre el espacio social y el espacio geográfico, reconociendo que los agentes sociales -al igual que los objetos-, según su posición en el espacio social, construyen capitales simbólicos, y así las estructuras sociales terminan por convertirse en estructuras mentales y sistemas de preferencias, que expresan jerarquías y distancias sociales. A esa traducción del espacio social en el espacio físico la denomina "efectos de lugar"(72 p.119).
Recuperamos el territorio, no desde una concepción romántica, sino que reconocemos, como bien señala Milton Santos ${ }^{(7)}$, que puede ser hogar o cárcel para el sujeto, por eso mismo debe ser trabajado de manera integral y diacrónica, buscando dar cuenta de la demanda técnica en tanto saber situado, pero sin dejar de tener presente los componentes ideológico-culturales y económicopolíticos que constituye cada problema. El territorio es una construcción humana, inacabada, en permanente movimiento y transformación ${ }^{(7)}$.

\section{Tiempo y espacio}

Los cambios en las ideas sobre el espacio y el tiempo son centrales para entender la modernidad y sus momentos, y cómo han afectado los procesos productivos, los valores individuales y los procesos sociales $y$, por lo tanto, la producción de nuevas subjetividades ${ }^{(73)}$, y cómo se crea y legitima el poder social ${ }^{(10)}$, y allí el rol de la ciencia hegemónica es central. En 1915, Albert Einstein - desde la física, con la teoría general de la relatividad- produce un cambio en la concepción tiempo-espacio. Pero también el arte suele anticiparse a la ciencia: el libro Alicia en el país de las maravillas publicado en $1865^{(74)}$ o la película Matrix ${ }^{(75)}$ son algunos de los ejemplos que colocan en juego otras visiones sobre lo temporo-espacial.

La escolástica entendía el tiempo como el número o medida del movimiento, según un antes y un después, una condición de los seres temporales. En tanto, para Kant, era una forma a priori de la razón pura: espacio y tiempo eran categorías con las que la sociedad se organizaba ${ }^{(76)}$. Para Heidegger, el espacio era casi insignificante, un pasar, en el que lo temporal aparece como lo perecedero ${ }^{(10,77)}$. El tiempo tenía importancia en tanto misterio en el cual se da la existencia, en un proceso de llegar a ser ${ }^{(77)}$.

Marshall Berman entiende a la modernidad como una manera de experimentar el tiempo y el espacio ${ }^{(78)}$, conceptos interpretados de manera diferente según la época, tanto en 
el ámbito de la vida privada como de la vida pública. En la modernidad ambos conceptos aparecen, desde el sentido común, exentos de conflictos y ambigüedades, acompañando de manera subordinada al progreso ${ }^{(78)}$.

En el relato de la modernidad, el futuro aparece como promesa de progreso, el pasado, como lo dejado atrás por el progreso, en tanto que el presente será irrelevante por su "fugacidad". Se asume que el futuro es predecible y así se podrá controlar la naturaleza y asegurar el progreso. Esa lógica de lo temporal se encuentra en la planificación, la que ignora el viejo proverbio chino que afirma: "el arte de la predicción es muy difícil, sobre todo cuando se quiere predecir el futuro".

Para Walter Benjamin el futuro era algo vacío y homogéneo, por lo que formula el concepto de "tiempo ahora" que entiende al presente como pasado del futuro y como futuro del pasado ${ }^{(79,80)}$, asignándole una relevancia central al presente. Ideas similares encontramos en Nietzsche quien, en su obra Así habló Zaratustra, piensa las tres fases del tiempo desde la eternidad como continuo presente $^{(81)}$. Las concepciones de Benjamin contradicen la idea del tiempo dominante en la racionalidad eurocéntrica, la cual comprime el presente, al que concibe como fugaz y lo transforma en algo cuasi inexistente, a la vez que expande el futuro, a través de una representación lineal del tiempo. Santos recupera de Ernest Bloch la siguiente reflexión: si solo vivimos en el presente, no se comprende que sea tan pasajero. Esto lleva a reformular de manera radical la concepción del tiempo dominante en nuestras epistemes ${ }^{(10}$ p.151).

La idea ya mencionada de Benjamin de "tiempo ahora" refuerza el concepto de acción que, trasladado al territorio, rompe con la hipótesis de una solución externa, al poner en juego las fuerzas sociales frente a los problemas $^{(79,80)}$. Ante la pregunta ¿cuándo?, la modernidad colocaba la respuesta en el futuro, pero a partir de Benjamin la respuesta está en el presente, con lo cual la idea de "tiempo ahora" construye un puente conceptual para la acción. Este proceso demanda un sujeto capaz de formularse preguntas que den lugar a la acción, a la que entendemos como interacción no necesariamente racional ni teleológica, compuesta por elementos de la razón, del deseo, y de la cultura en combinaciones inciertas. Trabajar el tiempo presente como tiempo de la acción no significa negar la importancia del pasado ni del futuro, a los cuales rescatamos a través de las siguientes preguntas: ¿por qué? para encontrar los significados del pasado, y ¿para qué? para encontrar los sentidos del futuro ${ }^{(82)}$, sin por ello entenderlo como predecible, pero aceptando la proyección del deseo.

Santos señala dos procedimientos centrales en su Epistemología del Sur, obra en la que se identifica la influencia de la idea de "tiempo ahora" de Benjamin. Así, define al presente como un pasado incompleto $y$, al futuro, como presente incumplido en su momento de incumplimiento, por lo que propone un doble trabajo sobre el presente: como un pasado incompleto, o como un presente incumplido.

Tanto Benjamin, como Bloch y Santos le asignan centralidad al presente, dado que las acciones se dan en el presente y no en el futuro ${ }^{(10)}$. Santos propone invertir la lógica dominante y postula expandir el presente y reducir el futuro para crear un espacio-tiempo que dé cabida a las infinitas experiencias sociales existentes en un proceso de traducción sin sacrificar identidades ${ }^{(10)}$. En este sentido, Castoriadis entiende que "el tiempo es nada o es creación"(83).

Santos recupera de Bloch el concepto "todavía no"(10), como alternativa al pensamiento binario del todo/nada que expresa lo estático. El concepto de "todavía no", que no es "todo" ni "nada", en tanto dimensiones estáticas del pensamiento occidental, no tiene sentido ni dirección y, por lo tanto, puede terminar en desastre o esperanza ${ }^{(10)}$.

La concepción del tiempo dominante nos lleva a señalar la tensión entre medidas urgentes y cambios civilizatorios ${ }^{(10)}$. Sergio Arouca, referente de la reforma sanitaria brasileña, afirmaba que la reforma era un proyecto civilizatorio y no un proyecto técnico-gerencial, ya que se precisaban valores que eran propios de la civilización humana ${ }^{(84)}$. 
La idea de tiempo no debe confundirse con lo urgente, donde nadie puede detenerse a pensar, el ritmo se acelera, enceguece y arrastra todo, y lo urgente desplaza a lo importante. Esa "locura" que priva de libertad al sujeto deja como consecuencia ansiedad, depresión y estrés. Paul Virilio sostiene que la velocidad rige y destruye todo $y$, en esa destrucción, genera el olvido y la visión del espacio entra en crisis, amenazada por el tiempo ${ }^{(85,86)}$. Es esa urgencia y la ilusión en el futuro lo que lleva a que se planifique lo que no se hace y se haga lo que no se planifica. Hay más olvido que memoria ya que la apuesta es definir el futuro, el mismo que los textos sagrados del judaísmo prohíben explorar por ser propiedad del mesías. En los tiempos actuales, todo transcurre muy rápido, no hay tiempo para pensar, solo se trata de hacer -de manera irreflexiva- y para ello el sujeto cartesiano exige herramientas buscando la solución en lo instrumental, incapaz de pensarse a sí mismo, olvidando los fracasos sistemáticos de su accionar instrumental en el campo social.

En una sociedad totalmente moderna, la tragedia de la modernización -incluyendo su héroe trágico- Ilega naturalmente a su fin. Una vez que el desarrollista ha eliminado todos los obstáculos, el mismo se interpone en su camino, y debe desaparecer. ${ }^{\text {(77 p.62) }}$

\section{Objetivos y procesos}

La idea de objetivos es central a la programación y conlleva una noción de linealidad, causalidad y certidumbre, apropiada para problemas simples, pero no para problemas complejos. Para estos últimos se corresponde la idea de procesos que, en general, involucran distintos actores, objetos e intereses en un devenir atravesado por incertidumbres, razón, deseo, cultura, conflictos y azar. La idea de procesos es más pertinente para el territorio que la idea de objetivos, dado que esta última, en tanto formulación normativa requiere, para su cumplimiento, de alta concentración de poder y/o hegemonía cultural, y aun así presenta grados de incertidumbre. La idea de objetivos -dominio de lo estático- es más cercana a la cultura occidental, mientras que la de procesos -dominio de lo dinámico- se aproxima más a la cultura oriental.

El proceso no tiene como finalidad el incumplimiento, sino que debe tender a su realización, sin por ello ignorar la condición diacrónica del juego social ${ }^{(87,88)}$. En el territorio, el diagnóstico es de poca utilidad ya que la foto nunca es la película, así que debemos permitirnos jugar. El "debe ser", propio de la planificación normativa, ignora el juego y exalta el diagnóstico, por lo que no puede tomarse como punto de partida sino, a lo sumo, como el punto de llegada, que dará inicio -seguramente- a otros procesos, marcados siempre por la incertidumbre, con excepción de los problemas simples, en los que los saberes técnicos normados suelen tener fuerte impacto. Pero no son esos los problemas que dominan el juego social en el territorio.

Luego de su experiencia en la planificación normativa, Mario Testa reflexiona sobre el método CENDES/OPS y afirma: "le dimos valor 0 a una variable cuyo único valor no podía ser $0 "$. ¿Y cuál era esa variable?: el poder $y$, por lo tanto, el conflicto. Varios años más tarde, en Montes Claros, estado de Minas Gerais, Brasil -cuna del proceso que culmina en la Reforma Sanitaria Brasileña-, Mario Testa, en un trabajo de asesoría en salud que realiza junto a Mario Hamilton, un médico le dice: "no se trata de fijar normas sino de desencadenar procesos". Años más tarde, completa aquella frase con la pregunta ¿para qué desencadenar procesos?, y se responde: "para construir nuevos actores sociales" $y$, ante un nuevo ¿para qué?, afirma: "para instalar otros temas de discusión en la agenda del Estado". Ese conjunto de ideas son centrales en su pensamiento y reflejan su autocrítica sobre su época de planificador ${ }^{(12,89,90,91)}$.

Para el homo academicus, la idea de pensar en términos de procesos -y no de objetivos- representa un obstáculo epistemológico 
muy fuerte, ya que su historia de socialización estructuró la idea del cumplimiento de objetivos y en ello se basa su cosmovisión (plano de la trascendencia). Aunque si lo hacemos reflexionar, reconocerá que, en general, cumple muy pocos de los objetivos que se plantea. Y si le pedimos que analice retrospectivamente su historia vital y laboral, y examine si sus logros fueron parte de una lógica de objetivos o de procesos, descubrirá una realidad no pensada que lo estructura, en la que la mayoría de sus logros son parte de procesos relacionados al deseo, más que a la razón -plano de la inmanencia-, y la mayorías de sus obras inconclusas se relacionan con objetivos. La idea del devenir y el rol del deseo en las acciones están lejos de poder ser pensados por el sujeto cartesiano, aunque se demuestre que es central en sus prácticas. Guattari asocia la idea del devenir con lo que Ilya Prigogine denominó "procesos disipativos" en tanto rompen con la idea tradicional de lo lineal y del equilibrio(87,88).

\section{Potencia y caos}

En la modernidad, las obras de Baruch Spinoza y Friedrich Nietzsche fueron pioneras en trabajar el concepto de potencia ${ }^{(20,92)}$, el cual no fue -ni es- parte de los paradigmas de la ciencia "normal"(93), a pesar de que los sujetos que habitan en el territorio expresan en sus relaciones no solo poder, sino también potencia y caos.

La idea de potencia se encuentra en Aristóteles en relación con la idea de acto, a tal punto que usa de manera indistinta los conceptos de potencia y posibilidad. Solo sobre la base del acto se puede entender lo potencial. La relación potencia-acto se entiende como el paso de entidades menos formadas a entidades más formadas, lo que expresa lo dinámico de la relación ${ }^{(36)}$. La potencia se define como "el poder que tiene una cosa de producir un cambio en otra cosa [...] es la potencialidad residente en una cosa de pasar a otro estado" 36 ${ }^{\text {p.2863) }}$. El acto precede a la potencia, la que representa una capacidad que puede ser actuada. La potencia es trabajada por Nietzche como voluntad de poder en tanto acto de libertad y superación. Para Nietzche, todo querer es un querer ser más ${ }^{(20)}$. Para Deleuze, los sujetos son potencias tanto en acciones como en pasiones, y no se definen por la esencia, ni por el juicio de los sabios, tal la propuesta del derecho natural ${ }^{(9)}$.

El territorio no siempre representa un juego pautado, muchas veces expresa el caos, lo impredecible, que no es sinónimo de desorden. El caos no fue objeto de la ciencia, que con su concepción determinística y lineal de los fenómenos lo desterró para preservar "el orden y el progreso", expresión clave del positivismo. Recién con el desarrollo de la teoría del caos y los sistemas complejos, entendidos como sistemas dinámicos muy sensibles a las variaciones en las condiciones iniciales, el caos alcanza estatus científico. El caos expresa cómo pequeñas variaciones en las condiciones iniciales pueden implicar grandes diferencias en el comportamiento futuro, lo que imposibilita la predicción. Esos conceptos se ubican en las antípodas de la planificación/programación que pretende predecir el futuro.

El trabajador sociosanitario reconoce el caos como parte del territorio pero no puede entenderlo dado que su propia configuración epistémica se lo imposibilita porque le llega codificado -dotado de significación- por la cultura (incluyendo en ella a la ciencia). Esa codificación -expresión de lo colonialsustituye la experiencia, tal como señala Magariños de Morentín: "El hombre no tiene frente a sí un mundo sino un espejo de sus propios sistemas semióticos de identificación, de modo que no selecciona lo que existe en el mundo sino lo que de conocido percibe en el mundo" ${ }^{\prime \prime 4}$ p.88). Por lo cual cada trabajador leerá la realidad a partir de la "clausura simbólica" que opere en ese instante, mientras que la ciencia y los medios realizarán un proceso industrializado de construcción/fabricación de la realidad ${ }^{(94)}$.

En esa línea de pensamiento, los programas actúan como clausuras simbólicas sobre la percepción de la realidad de los sujetos, y los alejan de las ideas de potencia y caos con las cuales conviven en el juego 
social. Deleuze señala que el libro, en tanto espejo del mundo, expresa el triunfo de la escolástica ${ }^{(9)}$. De allí la exportación de ideología desde el centro hacia la periferia y la necesidad de toma de conciencia del significado de la ideología que han recibido, o siguen recibiendo, los pueblos del sur desde los sistemas centrales de poder ${ }^{(95)}$.

\section{Razón y deseo: programas y cartografías}

Deleuze y Guattari desarrollan la idea de territorio junto a los conceptos de desterritorialización y reterritorialización ${ }^{(9)}$. Para ellos, el territorio ya no es solo el espacio de lo vivido sino también un sistema percibido, en el que conviven procesos de agenciamientos que permiten romper con lógicas codificadas o sobrecodificadas, espacios y estructuras que no aportan más que perturbaciones y deformaciones en vez de llevar más lejos a las máquinas deseantes ${ }^{(87,88)}$. El deseo, en sus textos, supera el lugar que Freud le asignó - los límites de la familia en tanto lugar de lo privado-, por el contrario, lo consideran como un principio inmanente, de allí lo de producción deseante, en el sentido de que el deseo hace fluir y no cesa de efectuar el acoplamiento de flujos continuos y de objetos parciales

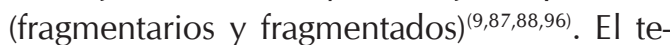
rritorio solo puede albergar caos o armonías provisionales, señalan estos autores que entienden a los territorios como fuera de nuestro alcance, ya que se están trazando y, por lo tanto, no somos más que una línea y solo nos queda cartografiar las estrategias del deseo en el campo de lo social y la producción de subjetividades que de allí surgen ${ }^{(9,87)}$.

Entienden que el territorio está atravesado por flujos de distintas intensidades y direcciones ${ }^{(9,88)}$. En él se configuran estratos -capturas- que aprisionan intensidades o fijan singularidades, constituyendo moléculas que pueden $-\mathrm{O}$ no- confluir en estructuras molares ${ }^{(9,88)}$. Para Deleuze y Guattari, los individuos y los grupos están constituidos por tres tipos de líneas que los atraviesan y componen:
- línea de segmentaridad rígida o molar que delimita objetos, sujetos, representaciones y que, con sus sistemas de referencia, corresponde al plano de la organización y, por lo tanto, marca, delimita y planifica;

- línea de segmentaridad flexible o molecular que corresponden a los flujos, a los devenires, a las transiciones, a las intensidades, a las nuevas composiciones que no coinciden exactamente con el segmento, ya que procede por umbrales y va a constituir devenires.

- línea de fuga o de desterritorialización -entre las que oscilan las líneas anteriores-que es segmentaria, es abstracta, no preexiste sino que se traza, se compone y no se sabe de antemano si va a funcionar como línea de fuga, o qué va a interceptarla $a^{(9,87,88)}$.

La lógica axiomática -propia de la planificación y los programas-, lejos de trazar líneas de fuga creadoras y procesos de desterritorialización, bloquea todas las líneas y las somete a un sistema puntual. Así logra detener y cristalizar la creación de la acción, en tanto novedad, la que se reduce a mera repetición ${ }^{(9,88)}$. La planificación y la programación representan, en el territorio, la línea de segmentaridad dura que niega el devenir. Sin embargo, son esas líneas las que definen la necesidad de cartografiarlas para aproximarnos a interpretar lo social que allí se produce y/o reproduce.

Tanto para Deleuze como para Guattari, la territorialidad es una característica central de los agenciamientos, ya que son creados en el territorio, en un movimiento de desterritorialización y reterritorialización que se repite de manera incesante ${ }^{(9,88)}$. El agenciamiento es la unidad mínima, no es la palabra, ni la idea o el concepto, ni tampoco el significante en el territorio ${ }^{(9)}$. Es una noción más amplia que la de estructura, sistema o forma y tiene componentes heterogéneos -tanto del orden biológico, social, maquínico, gnoseológico, imaginario, etc.- que ponen en conexión ciertas multiplicidades pertenecientes a distintos órdenes ${ }^{(9,88)}$. Hay agenciamientos muy diferentes: mapascalcos, rizomas-raíces, con coeficientes de 
desterritorialización variables ${ }^{(9)}$. El agenciamiento es esencialmente libidinal e inconsciente, no produce bienes sino que mezcla cuerpos, en un conjunto de representaciones que desembocan en comportamientos, inversiones, en tiempos y espacios sociales, culturales, estéticos y/o cognitivos ${ }^{(9,87,88)}$.

Guattari revela que, en las sociedades industriales, existe toda una serie de microrredes de poder y disciplina que conforman "un régimen político miniaturizado" e invisibilizado que forma parte del sentido común de los individuos. Todo es político y a la vez todo es macropolítica y micropolítica, así el territorio expresa la lucha $-\mathrm{o}$ resistencia- por su transformación, es decir es el espacio de la micropolítica en tanto afectos y conversaciones que expresan lo múltiple y lo relacional ${ }^{(96)}$. La micropolítica no sabe de "condiciones" es puro devenir en el plano de la inmanencia, es espacio del trabajo vivo y de los vínculos ${ }^{(9,65,96)}$.

Los modelos organizativos hegemónicos del mundo industrial son antagónicos a la dinámica de los territorios, en los que conviven diseños arbóreos con diseños rizomáticos. Esto nos permite pensar a los trabajadores en el territorio como artesanos en un "ser ahí", arrojados al mundo, que -no pocas veces- tienen que pensar lo impensado, atravesados por el juego de la micropolítica, en la que se mezcla lo individual y lo colectivo, lo consciente y lo inconsciente, el deseo y la razón, todos elementos innegables de lo humano, que constituyen los procesos relacionales. Esos dispositivos están muy alejados de los organigramas, los cuales provienen de la configuración del ejército prusiano y se basan en la experiencia de la Iglesia católica apostólica romana y de los centuriones romanos $y$, como diseño organizacional, representan lo vertical arborescente (árbol-raíz) de naturaleza jerárquica, con centros de significancia y de subjetivación, otorgados por el lugar que ocupan las personas ${ }^{(9)}$.

El pensamiento no es arborescente $y$ cuando toma tal forma no hace más que proceder por calcos -copias- y así termina por no pensar ${ }^{(9)}$. En el territorio se producen otras dinámicas que nos obligan a pensar también en términos de rizomas ${ }^{(9)}$. La capilaridad y la porosidad del territorio permiten la invención de posibles, en tanto lo arborescente atraviesa las instituciones y los aparatos de poder y se mueve en una lógica centrada-genealógica, de relaciones binarias que siempre fijan un punto, un orden ${ }^{(9,88)}$. A su vez, lo rizomático desarrolla una lógica descentrada conformada por líneas, al contrario de las estructuras que se definen por un conjunto de puntos y posiciones, de relaciones binarias entre los puntos y de relaciones biunívocas entre las posiciones. El rizoma es combinación de un punto con cualquier punto, no se deja reducir a uno, ni a lo múltiple, no se conforma por unidades, sino por dimensiones, no tiene ni principio ni fin y puede establecer conexiones transversales sin que pueda ser centrado o clausurado, posee múltiples entradas, salidas y líneas de fuga $^{(9}$ p.13). Hay una relación de tensión y de complementariedad entre el árbol raíz y el rizoma, no son dos modelos que se oponen, ya que mientras uno actúa como modelo y como calco trascendente, el otro actúa como proceso inmanente que destruye el modelo y esboza un mapa, incluso constituyendo sus propias jerarquías. Por eso se reconocen líneas rizomáticas en los árboles, y puntos de arborescencia en el rizoma ${ }^{(9.26)}$.

En la cultura occidental predomina el pensamiento arbóreo, que se relaciona con el dominio del plano de la trascendencia en tanto representación de una realidad exterior -que trasciende al sujeto. En la cultura oriental domina el plano de la inmanencia, como fenómeno psíquico inmanente al sujeto, que no lo trasciende ya que es inherente a él y va unido de un modo inseparable a su esencia, aunque racionalmente pueda distinguirse de ella ${ }^{(9)}$. Deleuze afirma que es necesario trabajar el plano de la inmanencia en oposición al plano de trascendencia, concebido como una realidad superior ${ }^{(9)}$. Por el contrario, el plano de la inmanencia es el plano de los acontecimientos, de las singularidades y de las intensidades en continuo movimiento ${ }^{(9,88)}$.

La idea de rizoma nos permite entender otras configuraciones en el territorio, ya que 
no se trata de culturas a doblegar ni de territorios a ocupar, sino de trabajar en la diversidad de culturas que el territorio arrastra, produce y acumula bajo formas de árbol-raíz y de rizomas, en procesos de agenciamientos que señalan la presencia de la micropolítica y el deseo ${ }^{(9,88,96)}$

El concepto de lugar soporta sin problemas el mapa, dado que ambos comparten sus situaciones estáticas y pueden dialogar sin conflictos. En cambio, para el territorio, el mapa resulta insuficiente, exige ser cartografiado en línea de manera de dar cuenta de lo dinámico y de las transformaciones, de la creación de nuevos sentidos y nuevos mundos, de las líneas de fuga, de las formaciones del deseo así como de aquellos dispositivos que van quedando obsoletos. La cartografía se transforma en teoría al rastrear esas intensidades que buscan expresión para entender las dinámicas del territorio, los agenciamentos, lo molecular y lo molar, la macro y la micropolítica, la raíz-árbol y lo rizomático, los poderes macro y micro, las potencias, etc. En ese proceso de cartografiar no hay protocolos posibles ya que su práctica es netamente micropolítica y singular. Ante ello, solo debe regir el imperativo de intervenir, de jugar, de desencadenar procesos sin certezas, pero fiel al deseo y a las apuestas que se generan, tratando que las acciones sean el puente entre la potencia y el poder $r^{(9,87,88,96)}$.

\section{Una ecología de saberes en el territorio}

Los conceptos desarrollados hasta aquí confrontan con los programas y nos señalan cómo estos últimos "programan" a sus ejecutores que responden de la misma manera ante diferentes problemas, en diferentes lugares y tiempos. ¿El éxito de los programas será robotizar a los trabajadores?

Aceptar la ecología de saberes ${ }^{(10)}$ implica una reformulación de las bases epistémicas del conocimiento dominante en las universidades y en la mayoría de los profesionales, independientemente de la carrera, la ideología política, la edad y el género.
En la lógica de la planificación-programación y en la de los territorios podemos identificar dos encadenamientos conceptuales, no necesariamente dicotómicos: uno propio de la cosmovisión occidental del mundo, formado por los conceptos poder, razón, plan, programa, objetivo, técnica, fundamentar, organigrama; y otro, subalterno, más relacionado a la cosmovisión oriental, conformado por los conceptos potencia, deseo, acción, devenir, proceso, cultura, fundar, rizoma.

La separación entre teoría y práctica, herencia de la escolástica, difiere de la invitación que realiza Santos a pensar que la comprensión occidental del mundo que nos constituye como sujetos epistémicos es muy limitada frente a la diversidad de saberes y de "otros mundos" que son invisibilizados por la clausura simbólica que realiza el conocimiento hegemónico ${ }^{(10)}$. Por ello, debemos enfrentar y superar el pensamiento que naturalizó en nosotros -en tanto sujetos epistémicos- el universalismo y reconocer que aprendimos una teoría general a pesar de su irrealidad, lo cual es funcional para negar el trabajo de traducción de los distintos saberes que se encuentran en el territorio ${ }^{(10,34)}$. Para romper con la herencia de la razón moderna y el pensamiento occidental dominante es necesario acercarse a otros presupuestos epistemológicos. De allí que Santos plantee la ecología de los saberes y la traducción intercultural como un pensamiento basado en experiencias prácticas, en luchas sociales y en trabajos de campo, tratando de evitar "los epistemicidios", proceso que explora más allá de los saberes científicos y procura que la traducción intercultural sea el procedimiento que posibilite entendimientos entre las diversas experiencias de lo territorial ${ }^{(10)}$.

Santos señala que vivimos en un tiempo de preguntas fuertes y respuestas débiles, dado que la crítica ha ido perdiendo los sustantivos para quedarse con los adjetivos. Esa sobreabundancia de adjetivos y anulación de sustantivos es clara expresión de la crisis del "homo academicus" que se traslada a la sociedad ${ }^{(97)}$, y expresa que "los conflictos epistemológicos son siempre, inseparablemente, 
conflictos políticos"(98 p.15) y, en tanto conflictos políticos, en nuestro continente, señalan su matriz colonial.

La experiencia social es mucho más amplia que la validada por la tradición científica y filosófica occidental, incluso por la ciencia social tal como la conocemos. Es necesario otro modelo de racionalidad, a la cual Santos Ilama razón cosmopolita, en contraposición a la razón indolente, que es la razón moderna tal como la venimos describiendo ${ }^{(4,10)}$. Santos fundamenta su propuesta en tres procedimientos sociológicos: la sociología de las ausencias, la sociología de las emergencias y el trabajo de traducción. Intenta así ir más allá de la comprensión del mundo que se hace desde occidente y que se relaciona con una singular idea del tiempo y el espacio. Para ello, propone expandir el presente (sociología de las ausencias) y contraer el futuro (sociología de las emergencias), y así crear la situación témporoespacial necesaria para conocer y valorizar las experiencias de los territorios y evitar el desperdicio de prácticas singulares que no pueden ser interpretadas por una teoría general, pero sí traducidas sin que pierdan su singularidad ${ }^{(10)}$

La sociología de las ausencias propone ampliar el presente, uniendo a lo real existente lo que le fue sustraído por la razón y produjo un desperdicio de experiencias. Busca expandir el campo de las experiencias sociales disponibles y multiplicarlas a través de la ecología de los saberes. Se propone transformar lo ausente en presente, los imposibles en posibles y así volver reales experiencias alternativas a las hegemónicas. Esto requiere sustituir la monocultura del saber por una ecología de saberes que libere las prácticas sociales de su carácter residual, y permita abrir espacios a las posibilidades de diferencias, que reconozca la multiplicidad y diversidad de prácticas sociales, y recupere lo local al desglobalizarlo. La sociología de las ausencias es un conocimiento argumentativo que más que demostrar persuade, convence, no es racional, es razonable ${ }^{(10)}$.

La sociología de las emergencias se propone expandir el campo de las experiencias posibles y para ello trata de contraer el futuro y sustituir ese vacío que constituye el futuro, por posibilidades plurales y concretas, utópicas y realistas, que se construyen en el presente a partir de las actividades de cuidado que actúan tanto sobre las posibilidades (potencialidad), como sobre las capacidades (potencia). Así, se sustituye la idea mecánica de determinación por la idea axiológica del cuidado, que reemplaza a la mecánica del progreso y a la idea de planificación. El elemento subjetivo lo constituye la conciencia anticipatoria y el inconformismo, que busca una relación más equilibrada entre experiencias y expectativas, por lo que le asigna importancia a las "señales" y a las "pistas", reconociendo en ellas las semillas de lo que puede ser decisivo en el futuro. El "todavía no" es la manera en que el futuro se inscribe en el presente y lo expande ${ }^{(10)}$.

La traducción que propone Santos ${ }^{(10)}$ se basa en la imposibilidad de una teoría universal. La traducción debe permitir la comunicación e inteligibilidad recíproca entre las experiencias, sin desconocer lo subalterno en cada una de ellas, así como sus componentes artesanales no replicables. Ese proceso de traducción incluye tanto teorías como prácticas que precisan deconstruir las epistemes eurocéntricas, coloniales y neocoloniales que producimos y/o reproducimos consciente $y / o$ inconscientemente. Lo cual requiere no solo un trabajo técnico, sino también un trabajo emocional, político e intelectual que nos lleve a preguntarnos sobre ¿qué traducir?, ¿entre qué?, ¿cuándo?, ¿quién traduce?, ¿con qué objetivos? ${ }^{(10)}$.

El trabajo cotidiano en el territorio es centralmente micropolítica, y en ella participan los trabajadores a través del trabajo vivo en acto, por el cual tienen la potencialidad de inventar sus cotidianos a través de apuestas $^{(65,66)}$. Para las especificidades técnicas que el territorio requiera, los equipos deberán contar con apoyo especializado matricial ${ }^{(99)}$. En síntesis, se propone comprimir el futuro para ampliar el presente $y$ así tener más acción y menos planificación, es decir, menos predicción y más apuestas, lo que significa más acción centrada en el 
fundar y menos discursos centrados en el fundamentar. Todo ello exige hacer presente al presente, más "tiempo ahora", más "todavía no" y más procesos.

\section{PARA SEGUIR PENSANDO}

Vivimos tiempos paradojales: mientras, por un lado, nos recorre un sentimiento de urgencia por cambiar la realidad y reclamamos que es necesario hacer algo ya, por otro, hay un sentimiento casi opuesto acerca de que las transformaciones que necesitamos son a largo plazo, relacionadas a dimensiones culturales, civilizatorias. Es decir que no es posible cambiar todo ahora y no basta con tomar el poder; por el contrario, es necesario transformar antes este Estado moderno, cuya crisis es producto del neoliberalismo. Se trata, de crear o refundar otro Estado sin olvidar la historia, en un proceso de prácticas fundantes en las instituciones y en el territorio ${ }^{(10,32,50,100)}$, ya que el descrédito sobre los programas no implica el descrédito de los problemas en el territorio(10).
Los territorios son un campo fértil para las preguntas. Sin embargo, repetimos las respuestas, tanto en las prácticas como en los discursos. Se dice que hay dos formas de fracasar: pensar sin actuar y actuar sin pensar, $y$ no es infrecuente que ambas situaciones se cumplan. Dejamos de pensar. ¿Por qué? ${ }^{(15)}$. ¿Podremos permitirnos el ejercicio de las preguntas para volver a pensar?

Es necesario entender que no hay un método ni una técnica para intervenir en el juego social del territorio. Este texto expresa el esfuerzo por salir de los modelos racionalistas que dominan las formas de trabajar y de pensar lo social, para pasar a dinámicas marcadas por el juego, el devenir y la incertidumbre que son propias de lo social. Desde allí nos ubicamos para poder finalizar este trabajo de una manera abierta, sin fórmulas ni recetas, y con más preguntas que al momento de comenzar a escribirlo. Solo nos acompaña la certeza de la necesidad de volver a pensar en salud más allá de lo biomédico, y así encontrarnos con las preguntas que conforman ese juego infinito que constituye lo social como un todo ${ }^{(101)}$.

\section{REFERENCIAS BIBLIOGRÁFICAS}

1. Bourdieu P. "Los intelectuales de hoy": Entrevista a Pierre Bourdieu. Los Sueños de Piedra [Internet]. 2012 [citado 10 feb 2016]. Disponible en: https://goo.gl/hbg6R1.

2. Horkheimer M. Teoría crítica. Buenos Aires: Amorrortu; 2008.

3. Horkheimer M. Crítica de la razón instrumental. Buenos Aires: Sur; 1973.

4. Horkheimer M, Adorno T. Dialéctica del Iluminismo. Buenos Aires: Sudamericana; 1987.

5. Santos M. Território e sociedade. São Paulo: Editora Fundação Perseo Abramo; 2001.

6. Santos M. A natureza do espaço: Técnica e tempo, razão e emoção. São Paulo: Hucitec Editora; 1997.
7. Santos M. Por uma geografia nova: Da crítica da geografia a uma geografia crítica; São Paulo: Hucitec Editora; 1996.

8. Bourdieu P, Wacquant I. Una invitación a la sociología reflexiva. Buenos Aires: Siglo XXI Editores; 2008.

9. Deleuze G, Guattari F. Mil mesetas: capitalismo y esquizofrenia. Valencia: Pre-textos; 1988.

10. Santos BS. Una epistemología del sur. Buenos Aires: Siglo XXI Editores, CLACSO; 2013.

11. Foucault M. Poderes y estrategias. En: Un diálogo sobre el poder y otras conversaciones. Madrid: Alianza; 1985.

12. Menendez E. El modelo médico y la salud de los trabajadores. Salud Colectiva. 2005;1(1):9-32.

13. Testa M. Pensar en salud. Buenos Aires: Lugar Editorial; 1993. 
14. Heller A, Fehér F. Biopolítica: La modernidad y la liberación del cuerpo. Barcelona: Ediciones Península; 1995.

15. Heidegger M. ¿Qué significa pensar? Madrid: Trotta; 2008.

16. Bachelard G. Epistemología. Barcelona: Anagrama; 1974.

17. Marcuse H. El hombre unidimensional. México DF: Planeta; 1968

18. Tovilla P. Bourdieu: una introducción. Buenos Aires: Quadrata; 2010.

19. Castoriadis C. Figuras de lo pensable. Buenos Aires: Fondo de Cultura Económica; 2001.

20. Heidegger M. Nietzsche. Barcelona: Destino; 2000 .

21. Varsavsky O. Ciencia, política y cientificismo. Buenos Aires: Centro Editor de América Latina; 1974.

22. Bautista JJ. ¿Qué significa pensar desde América Latina? México DF: Akal; 2014.

23. Rosanvallon P. La nueva cuestión social: Repensar el Estado providencia. Buenos Aires: Ediciones Manantial; 1995.

24. Organización de los Estados Americanos. Alianza para el progreso [Internet]. Washington DC: OEA; 1967 [citado 10 feb 2016]. Disponible en: http://goo.gl/pjoXJF.

25. Parson T. El sistema social. Madrid: Alianza; 1999.

26. Presbich R. El desarrollo económico de la América Latina y algunos de sus principales problemas [Internet]. CEPAL [citado 10 feb 2016]. Disponible en: http://goo.gl/uROyjB.

27. Presbich R. Hacia una dinámica del desarrollo latinoamericano [Internet]. Mar del Plata, Buenos Aires: CEPAL; 1963 [citado 10 feb 2016]. Disponible en: http://goo.gl/pOjxxD.

28. Cardozo FH, Faletto E. Dependencia y desarrollo en América Latina. Buenos Aires: Siglo XXI Editores; 2003.

29. Piketty T. El capital en el siglo XXI. Buenos Aires: Fondo de Cultura Económica; 2014.

30. Laclau E. La deriva populista y la centroizquierda latinoamericana. Nueva Sociedad. 2006;(205):56-61.
31. Bertalanffy LV. Teoría general de los sistemas: fundamentos, desarrollo, aplicaciones. México: Fondo de Cultura Económica; 1995.

32. Matus C. Adiós, señor presidente. Buenos Aires: Ediciones de la UNLa; 2007.

33. Freud. S. El malestar de la cultura. En: Sigmund Freud: Obras completas. Buenos Aires: Amorrortu Editores. p. 57-144.

34. Luz M. Natural, racional, social. Buenos Aires: Lugar Editorial; 1997.

35. Cerdeiras R. La subversión de nuestro siglo. Colección Milenio. 1994;(2):8-34

36. Ferrater Mora J. Diccionario de Filosofía. Barcelona: Ariel Filosofía; 1994.

37. Jaramillo A. La Universidad frente a los problemas nacionales. Lanús: Ediciones de la UNLa; 2003.

38. Dussel E. Filosofías del sur: descolonización y transmodernidad. México DF: Akal; 2015.

39. Freire P. Pedagogía del oprimido. Buenos Aires: Siglo XXI Editores; 2005.

40. Varsavsky O. Ciencia, política y cientificismo. Buenos Aires: Centro Editor de América Latina; 1974.

41. Matus C. Teoría del juego social. Buenos Aires: Ediciones de la UNLa; 2007.

42. Descartes R. Discurso del método. Buenos Aires: Losada; 1974.

43. Testa M. Pensamiento estratégico y lógica de programación (el caso de salud). Buenos Aires: Lugar Editorial; 1995.

44. Weber M. Ética protestante y espíritu del capitalismo. Madrid: Itsmo; 1990.

45. Centro de Documentación Pensar en Salud (CEDOPS). Curso Internacional de Especialización en Planificación de Sistemas de Salud [Internet]. Lanús: Instituto de Salud Colectiva, Universidad Nacional de Lanús [citado 1 mar 2016]. Disponible en: http://goo.gl/fv0jRx.

46. Uribe Rivera FJ. Planejamento e programação em saúde: um enfoque estratégico. São Paulo: Cortez Editora; 1989

47. Campos Souza GW, Merhy E, Nunes Duarte E. Planejamento sem normas. São Paulo: Hucitec Editora; 1989. 
48. Gallo E, Merhy E, Mendez Gonçalves RB. Razão e Planejamento: reflexões sobre política, estratégia e liberdade. São Paulo: Hucitec Editora; 1994.

49. Mintzberg $\mathrm{H}$. The rise and fall of strategic planning. New York: Simon \& Schuster; 1994.

50. Matus C. Las ciencias y la política. Salud Colectiva. 2007;3(1):81-91.

51. Bachelard G. La formación del espíritu científico. México DF: Siglo XXI Editores; 1991.

52. Mouffe C. En torno a lo político. Buenos Aires: Fondo de Cultura Económica; 2011.

53. Ortega Blake JA. Diccionario de planeación y planificación (un ensayo conceptual). México: Edicol; 1982.

54. Organización Panamericana de la Salud. Programación y Salud Pública. En: Programación de la Salud (Publicaciones Científicas No 111). Washington DC: OPS; 1965. p. 1-20.

55. Rubio Cebrain S. Glosario de economía de la salud (y disciplinas afines). Madrid: Díaz de Santos; 1995.

56. Pineault R, Daveluy C. La Planificación Sanitaria: conceptos, métodos, estrategias. Barcelona: Masson; 1992.

57. Angell M. La verdad acerca de la industria farmacéutica: cómo nos engaña y qué hacer al respecto. Bogotá: Norma; 2006.

58. Omran AR. The epidemiologic transition: a theory of the epidemiology of population change. The Milbank Memorial Fund Quarterly. 1971;(4):509-583.

59. Martínez Salgado C. Abrir la epidemiología. En: Eibenschutz HC, Tamez SG, González RG. ¿Determinación social o determinantes sociales de la salud? México DF: UAM; 2001. p.71-90.

60. Latour B. Nunca fuimos modernos. Buenos Aires: Siglo XXI Editores; 2007.

61. Spinelli $H$, Testa $M$. Del diagrama de Venn al nudo borromeo: recorrido de la planificación en América Latina. Salud Colectiva. 2005;1(3):323-335.

62. Midaglia C. Un balance crítico de los programas sociales en América Latina: Entre el liberalismo y el retorno del Estado. Nueva Sociedad. 2012;(239):79-89.
63. Ortega y Gasset J. 1937 La rebelión de las masas. Madrid: S.L.U. Espasa Libros; 2005.

64. Santos BS. Um discurso sobre as ciências. São Paulo: Cortez; 2003.

65. Merhy EE. Salud: cartografía del trabajo vivo. Buenos Aires: Lugar Editorial; 2006.

66. Franco TB, Merhy EE. Trabalho, produção do cuidado e subjetividade em saúde. São Paulo: Hucitec Editora; 2013.

67. Spinelli $\mathrm{H}$. El trabajo en el campo de la salud: ¿modelos artesanales o industriales? Investigación y Educación en Enfermería. 2015;33(2): 194-205.

68. Frei Betto. Martí e a Revolução Cubana [Internet]. Adital, 25 ene 2013 [citado 12 mar 2016]. Disponible en: http://goo.gl/8kmUkd.

69. Badiou A. El ser y el acontecimiento. Buenos Aires: Manantial; 1999.

70. Zourabichvili F. Deleuze: una filosofía del acontecimiento. Buenos Aires: Amorrortu Editores; 2011.

71. Harvey D. Condição Pós-Moderna. São Paulo: Loyola; 1993.

72. Bourdieu P. La miseria del mundo. Buenos Aires: Siglo XXI Editores; 2002.

73. Bleichmar S. No me hubiera gustado morir en los 90. Buenos Aires: Taurus; 2006.

74. Arenas B. Visiones del país de las maravillas. Santiago: Andres Bello; 1983

75. Palao JA, Crespo R. Matrix. Valencia: Nau Llibres; 2005.

76. Kant I. Crítica de la razón pura. Madrid: Tecnos; 2004.

77. Heidegger M. Ser y tiempo. México DF: Fondo de Cultura Económica; 2006.

78. Berman M. Todo lo sólido se desvanece en el aire. La experiencia de la modernidad. Madrid: Siglo XXI Editores; 1989.

79. Benjamin W. La dialéctica en suspenso. Buenos Aires: Arcis-LOM; 2002.

80. Benjamin W. Conceptos de filosofía de la historia. La Plata: Terramar; 2007.

81. Nietzsche F. Así hablaba Zaratustra. Madrid: EDAF; 1985. 
82. Giddens A. Las nuevas reglas del método sociológico. Buenos Aires: Amorrortu Editores; 1987.

83. Castoriadis C. O imaginário: a criação no domínio social-histórico. En: As encruzilhadas do Labirinto II: Os domínios do homem. Rio de Janeiro: Paz e Terra; 1987.

84. Arouca S. El dilema preventivista: contribución a la comprensión y crítica de la medicina preventiva. Buenos Aires: Lugar Editorial; 2008.

85. Virilio P. Velocidade e política. São Paulo: Estadía Liberdade; 1996.

86. Virilio P. El arte del motor. Buenos Aires: Manantiales; 1993.

87. Deleuze G, Guattari F. El antiedipo: capitalismo y esquizofrenia. Buenos Aires: Paidós; 2007.

88. Guattari F. Cartografía del deseo. Buenos Aires: La Marca; 1995.

89. Hamilton M. Vida de sanitarista. Buenos Aires: Lugar Editorial; 2010.

90. Testa M, Silva Paim J. Memoria e historia: diálogo entre Mario Testa y Jairnilson Silva Paim. Salud Colectiva. 2010;6(2):211-227.

91. Testa M. Saber en salud: la construcción del conocimiento. Buenos Aires: Lugar Editorial; 1997.
92. Chaui M. Política en Spinoza. Buenos Aires: Gorla; 2003.

93. Kuhn T. La estructura de las revoluciones científicas. México DF: Fondo de Cultura Económica; 1986.

94. Magariños de Morentín JA. El proceso de la significación y su comunicación. En: El mensaje publicitario. Buenos Aires: Edicial; 1991. p. 79-113.

95. Chavez F. Epistemología para la periferia. Lanús: Ediciones de la UNLa; 2012

96. Guattari F, Rolnik S. Micropolítica: Cartografías del deseo. Madrid: Traficantes de Sueños; 2006.

97. Bourdieu P. Homo Academicus. Buenos Aires: Siglo XXI Editores; 2008.

98. Bourdieu P. Los usos sociales de la ciencia. Buenos Aires: Nueva Visión; 2008.

99. Campos G. Gestión en salud. Buenos Aires: Lugar Editorial; 2001.

100. Spinelli H. El proyecto político y las capacidades de gobierno. Salud Colectiva. 2012;8(2): 107-130.

101. Latour B. Reensamblar lo social. Buenos Aires: Manantial; 2008. 